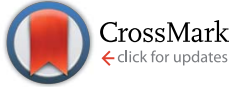

Cite this: RSC Adv., 2017, 7, 1154
Received 24th October 2016 Accepted 15th December 2016

DOI: 10.1039/c6ra25736d

www.rsc.org/advances

\title{
Chiral ionic liquid assisted synthesis of some metal oxides $\dagger$
}

\author{
Elena Husanu, ${ }^{* a}$ Valentina Cappello, ${ }^{\mathrm{b}}$ Christian Silvio Pomelli, ${ }^{\mathrm{a}}$ Jeremy David, ${ }^{\mathrm{b}}$ \\ Mauro Gemmi ${ }^{\mathrm{b}}$ and Cinzia Chiappe*a
}

A chiral ionic liquid with a natural alcohol based chain was used as a tailoring agent for the synthesis of simple and cost effective materials such as $\mathrm{ZnO}, \mathrm{CuO}, \mathrm{CuO}-\mathrm{ZnO}$ with peculiar morphology. The morphology and chemical composition of the microstructures were investigated by bright-field and scanning transmission microscopy (BF-TEM and STEM), energy dispersive X-ray spectroscopy (EDX), Fourier transform infrared spectroscopy (FTIR), and UV-VIS spectroscopy. Furthermore, the photocatalytic activity of $\mathrm{ZnO}, \mathrm{CuO}$ and $\mathrm{ZnO}-\mathrm{CuO}$ nanostructures was quantified for methylene blue (MB) dye. CuO needles had the lowest photocatalytic activity $(23.8 \%$ in $40 \mathrm{~min}$ ). Due to their peculiar forms, $\mathrm{ZnO}$ (flower like shape) and $\mathrm{ZnO} / \mathrm{CuO}$ (leaf like shape where $\mathrm{ZnO}$ nanoparticles were deposited) had the highest photocatalytic activity in $40 \mathrm{~min}$ (93.6\% for $\mathrm{ZnO}$ nanoparticles and $95 \%$ for $\mathrm{ZnO}-\mathrm{CuO}$ nanostructures).

\section{Introduction}

Metal oxide nanocrystals are of widespread interest because of their physical, chemical, optical and catalytic properties, which significantly differ from those of the corresponding bulk materials. Among these materials, zinc oxide ( $\mathrm{ZnO}$ ) and cupric oxide $(\mathrm{CuO})$ have gained a lot of attention owing to some specific features that make them attractive for application in different strategic fields. In particular, $\mathrm{ZnO}$ nanoparticles are versatile and low-cost materials characterized by a wide band gap and a large exciton binding energy (60 meV) at room temperature, together with a high transparency in the visible wavelength region and near UV region, high conductivity, and high piezoelectric constant. ${ }^{1}$ For these properties, ZnO nanoparticles have found application as additives for numerous materials and products such as plastics, ceramic, glass, cosmetic products, pigments etc. Furthermore, they can be integrated into a wide range of nanoscale devices such as optoelectronic, surface acoustic wave and piezoelectric devices, transparent conducting materials, solar cells and field emitters and can be used to produce antimicrobial textiles. ${ }^{2} \mathrm{ZnO}$ is indeed biocompatible, biodegradable and biosafe for medical and environmental applications. ${ }^{3}$ Related to these latter aspects, $\mathrm{ZnO}$ nanostructures have been proposed as photocatalysts for solar energy conversion and treatment of organic

${ }^{a}$ Dipartimento di Farmacia, Università di Pisa, Via Bonanno 33, Pisa, Italy. E-mail: cinzia.chiappe@farm.unipi.it; elenahusanu@gmail.com

${ }^{b}$ Istituto Italiano di Tecnologia, Center for Nanotechnology Innovation@NEST, Piazza San Silvestro 12, Pisa, Italy

$\dagger$ Electronic supplementary information (ESI) available. See DOI: $10.1039 / \mathrm{c} 6 \mathrm{ra} 25736 \mathrm{~d}$ pollutants, because of their low toxicity and high photocatalytic efficiency. However, the applicability in visible light is limited due to the wide band gap of the material, which results in low efficiency during solar photoconversion (UV light accounts only $4 \%$ of the total solar spectrum). Nonetheless, the introduction of electrically active dopants can enhance the visible light photocatalytic activity: several dopant agents have been used for this purpose. ${ }^{4-7}$ On the other hand, $\mathrm{CuO}$ nanoparticles have found application in many technological fields as doping materials in semiconductors, electronic chips, gas sensors, as catalysts for organic reaction, as passive and active components in solar cells and lithium batteries. However, the ability to inhibit the growth of microorganisms and antiviral properties has been also reported and $\mathrm{CuO}$ nanoparticles which are used in the fabrication of face masks, wound dressing and socks to give them biocidal properties. ${ }^{8-11}$ Composite nanostructures of these two metal oxides, with controlled composition and morphology, have been therefore considered able to give nanomaterials with improved properties with respect the single counterparts, which could find application in various fields of science and technology such as gas sensors, electrocatalysis, photocatalysis etc. The peculiar properties of these crystals arise from the surface to volume ratio and by the increased percentage of atoms at the grain boundaries that can be translated to enhanced reactivity. The possibility to design and control the shape and morphology of these inorganic nanomaterials is therefore a topic of great importance because of their peculiar electronic structure, bonding, surface energy and chemical reactivity. ${ }^{\mathbf{1 2}}$ In the recent years, a variety of transition metal nanoparticles has been synthesized with the help of ionic liquids (ILs), which are able to form stable nanoparticles 
dispersions, whose catalytic ability has been more times proved..$^{13} \mathrm{Au}$ nanosheets, PtPd bimetallic particles, CoPt alloy nanorods, metal oxides and chalcogenides nanostructures, and cyano-bridged magnetic nanoparticles have been prepared in these reaction media. ${ }^{\mathbf{1 4 - 1 6}}$ Actually, the term "ionic liquids" define an extremely large class of organic salts, liquid at/or near room temperature, characterized by peculiar and frequently different physico-chemical properties, that have generated an increasing interest as solvents or additives in numerous applications. Constituted exclusively of ions, ILs are indeed characterized by a low volatility, wide liquid temperature range, good thermal stability, good solvent power, an extreme structural versatility and the ability to guarantee high reactivity and selectivity when used as solvents and reaction media. ${ }^{\mathbf{1 7 - 2 1}}$ The practically infinite possibilities to modify anions and cations, also introducing specific functional groups on both ions, or in dissolving large amounts of metal salts, make ILs tunable materials able to affect positively reactivity and selectivity of chemical processes, contemporaneously favouring the development of greener procedures. A very important feature of ionic liquids is that they can form extended hydrogen bond giving rise to highly structured systems. In particular, in the emerging field of inorganic nanomaterial synthesis these media can act like solvents for the inorganic reactants and/or morphology templates for the products, giving rise to nanocrystals with peculiar or improved properties. ${ }^{22-24}$ Ultrasound synthesis of ZnO nanocrystals from zinc acetate and sodium hydroxide in bis(trifluoromethylsulfonyl)imide based ionic liquids (ILs) has been reported as a fast, easy, effective and highly morphology(nanorods or spheres) and size-selective approach to obtain $\mathrm{Zn}$ nanostructures of various dimensionalities. ${ }^{25,26}$

Analogously, $\mathrm{CuO}$ nanorods have been prepared via ultrasound-assisted synthesis in the room temperature ionic liquid 1-butyl-3-methylimidazolium bis(trifluoromethylsulfonyl) imide as a reaction medium. ${ }^{27}$ However, the ionic liquids that are often reported in literature in the synthesis of both metals and metal oxides nanoparticles are based on an imidazolium ring bearing a sufficiently long chain as substituent as cation and tetrafluoroborate $\left[\mathrm{BF}_{4}\right]^{-}$or hexafluorophosphate $\left[\mathrm{PF}_{6}\right]^{-}$as counter anions: these ionic liquids are suitable from the point of view of the solvents being hydrophobic but they not follow the standards of green chemistry, often releasing poisonous and corrosive $\mathrm{HF}^{28}$

Synthesis of efficient catalysts for purifying aqueous effluents from dyes utilizing the collective properties of self-assembling systems is very often a challenging process. In this study, we have focused our attention on the possibility to synthesize $\mathrm{ZnO}$, $\mathrm{CuO}, \mathrm{ZnO}-\mathrm{CuO}$ nanoarchitectures using, in water under ultrasound irradiation, an unusual IL, (S)-3-(3,7-dimethyloct-6-en-1yl)-1-methyl-1H-imidazol-3-ium methanesulfonate, i.e. a hydrophilic salt characterized however by a long chiral natural chain. More in detail, the nanoarchitectures have been synthesized by a simple method employing aqueous solutions of $\mathrm{Zn}^{2+}$ and/or $\mathrm{Cu}^{2+}$ salts, the chiral ionic liquid and $\mathrm{NaOH}$ without using high temperatures or high pressures. The ionic liquid has a natural alkyl chain, citronellol, and plays a strategic role on the shape of the metal oxides as a soft template and capping agent; moreover, it can be easily removed. The effect of the presence of the IL on nanoparticles morphology was investigated by TEM-STEM means. The chemical composition was analysed by EDX and FTIR spectroscopy. Furthermore, methylene blue (MB) dye was used as a model pollutant to evaluate the photocatalytic performances of the above nanoparticles synthesized.

\section{Results and discussion}

It is well known that $\mathrm{Cu}(\mathrm{OH})_{2}$ has orthorhombic structure and it is easily transformed into monoclinic $\mathrm{CuO}$ by heating. $\mathrm{ZnO}, \mathrm{CuO}$, CuO-ZnO nanostructures were successfully synthesized in water starting from aqueous solution of $\mathrm{Zn}(\mathrm{OAc})_{2}$ and/or $\mathrm{Cu}(\mathrm{OAc})_{2}$, in the presence of a proper amount of $(S)$-3-(3,7-dimethyloct-6-en-1yl)-1-methyl- $1 H$-imidazol-3-ium methanesulfonate (Scheme 1), by drop wise addition of an aqueous solution of $\mathrm{NaOH}$ and subsequent heating at $80{ }^{\circ} \mathrm{C}$ under ultrasonic irradiation.

The morphology of the isolated nanostructures was analysed by TEM and STEM imaging. Their crystalline nature was investigated through electron microdiffraction the unit cell of the nanocrystalline compounds has been determined and by indexing the corresponding rings patterns the unit cell of the nanocrystalline compounds has been determined. Fig. 1a shows the morphology of $\mathrm{ZnO}$ nanostructures obtained using the chiral ionic liquid (CIL) as template. It can be observed that the morphology of the sample is composed of flower shaped aggregates with a size in the 100-200 nm range. Electron microdiffraction patterns collected on blocks of several aggregates (illuminated area of $1 \mu \mathrm{m}$ in diameter) have a polycrystalline character and the diffraction rings can be indexed according to a zincite hexagonal cell (Fig. 1d and f). On the other hand, $\mathrm{CuO}$ nanostructures have a completely different shape. In Fig. 1b the sample appears constituted of particles with a smooth needle like shape with a length of 400-500 nm and a diameter of 10-15 $\mathrm{nm}$. In this case the microdiffraction patterns show again a polycrystalline nature, but the rings are more diffuse indicating a smaller grain size. The diffraction rings can be indexed according to the monoclinic cell of the $\mathrm{CuO}$ tenorite structure (Fig. 1e and $\mathrm{f}$ ). The formation of needlelike structures could be correlated to a significantly faster growth rate along one crystallographic direction which becomes the main axis of the needle. CuO nanowires have been previously obtained by conventional heating of $\mathrm{Cu}(\mathrm{OH})_{2}$ nanowires. Their formation was attributed by $\mathrm{Du}$ et al. to the heating

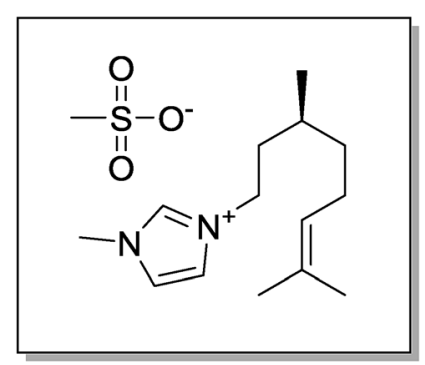

Scheme 1 Structure of the (S)-(3,7-dimethyloct-6-en-1-yl)-1methyl- $1 \mathrm{H}$-imidazol-3-ium methanesulfonate. 

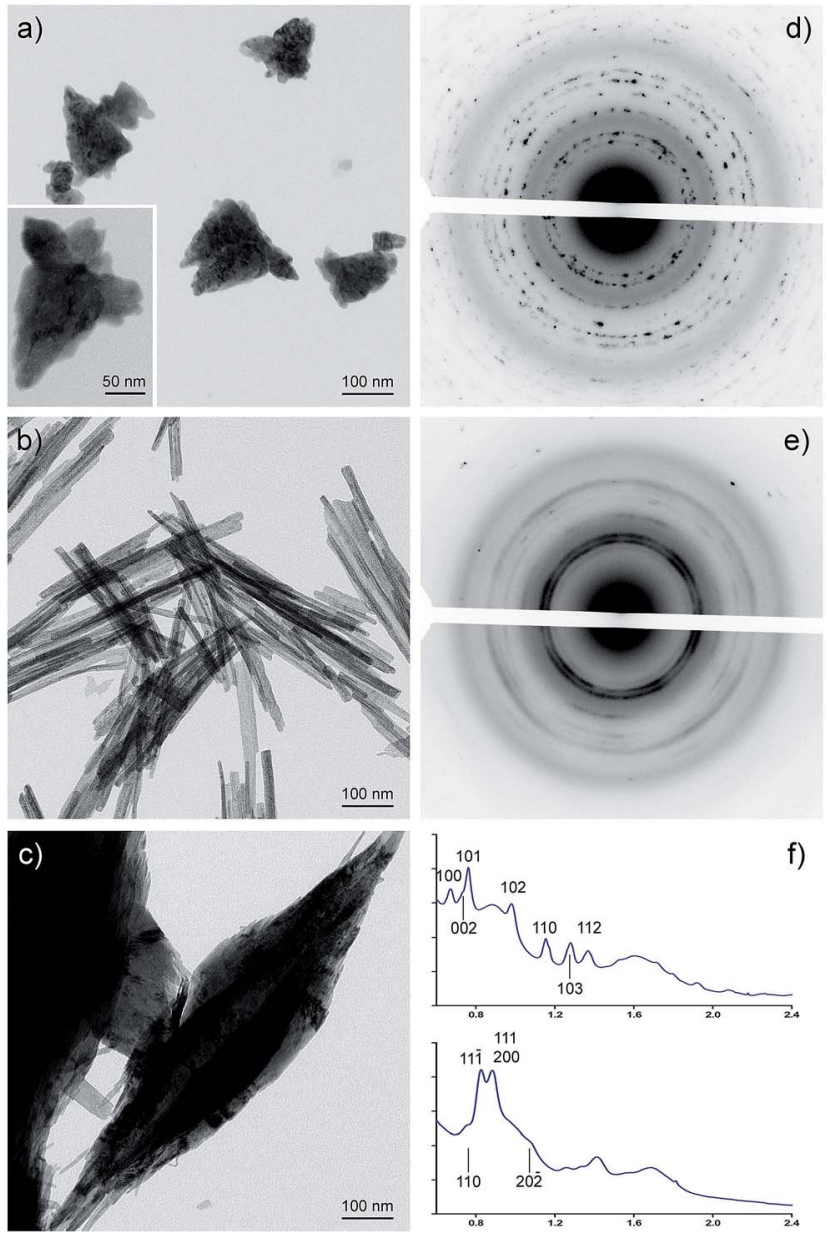

Fig. 1 TEM characterization of $\mathrm{CuO}$ and $\mathrm{ZnO}$ nanocomposites: (a) bright field TEM image of $\mathrm{ZnO}$ flower shaped aggregates. (b) Bright field TEM image of an aggregate of $\mathrm{CuO}$ needle like nanoparticles. (c) Bright field TEM image of $\mathrm{ZnO}-\mathrm{CuO}$ nanocomposites. (d) Microdiffraction collected on a block of aggregates of $\mathrm{ZnO}$ sample as the one displayed in (a) (illuminated area of $1 \mu \mathrm{m}$ in diameter). (e) Microdiffraction collected on an aggregate of needle like $\mathrm{CuO}$ nanoparticles (illuminated area of $1 \mu \mathrm{m}$ in diameter). (f) Radial integration of the patterns displayed in (d) (top) and (e) (bottom) with the main diffraction peaks indexed according to $\mathrm{ZnO}$ zincite hexagonal cell and $\mathrm{CuO}$ tenorite monoclinic cell respectively.

process, which should be able to favour the loss of water molecules maintaining the morphology of the starting material. ${ }^{29}$ On the other hand, rod-like particles of $10 \mathrm{~nm}$ in diameter and $30-100 \mathrm{~nm}$ in length have been obtained by Mundrig via ultrasound-assisted synthesis in 1-butyl-3-methylimidazolium bis(trifluoromethylsulfonyl)imide. ${ }^{26}$ Related to the sample of CuO-ZnO nanocomposite, TEM images of a typical sample shown in Fig. 1c reveals that the reaction product displays a leaf like structure with average length and width of $\sim 1 \mu \mathrm{m}$ and $\sim 0.3$ $\mu \mathrm{m}$, respectively. As a comparison, TEM observations were carried out on $\mathrm{CuO}$ nanoparticles prepared under identical conditions but in the absence of IL or using the corresponding racemic ionic liquid.

The morphology of $\mathrm{CuO}$ nanostructures remain unchanged when the racemic ionic liquid $\left(\mathrm{CIL}_{\mathrm{r}}\right)$ was employed in the
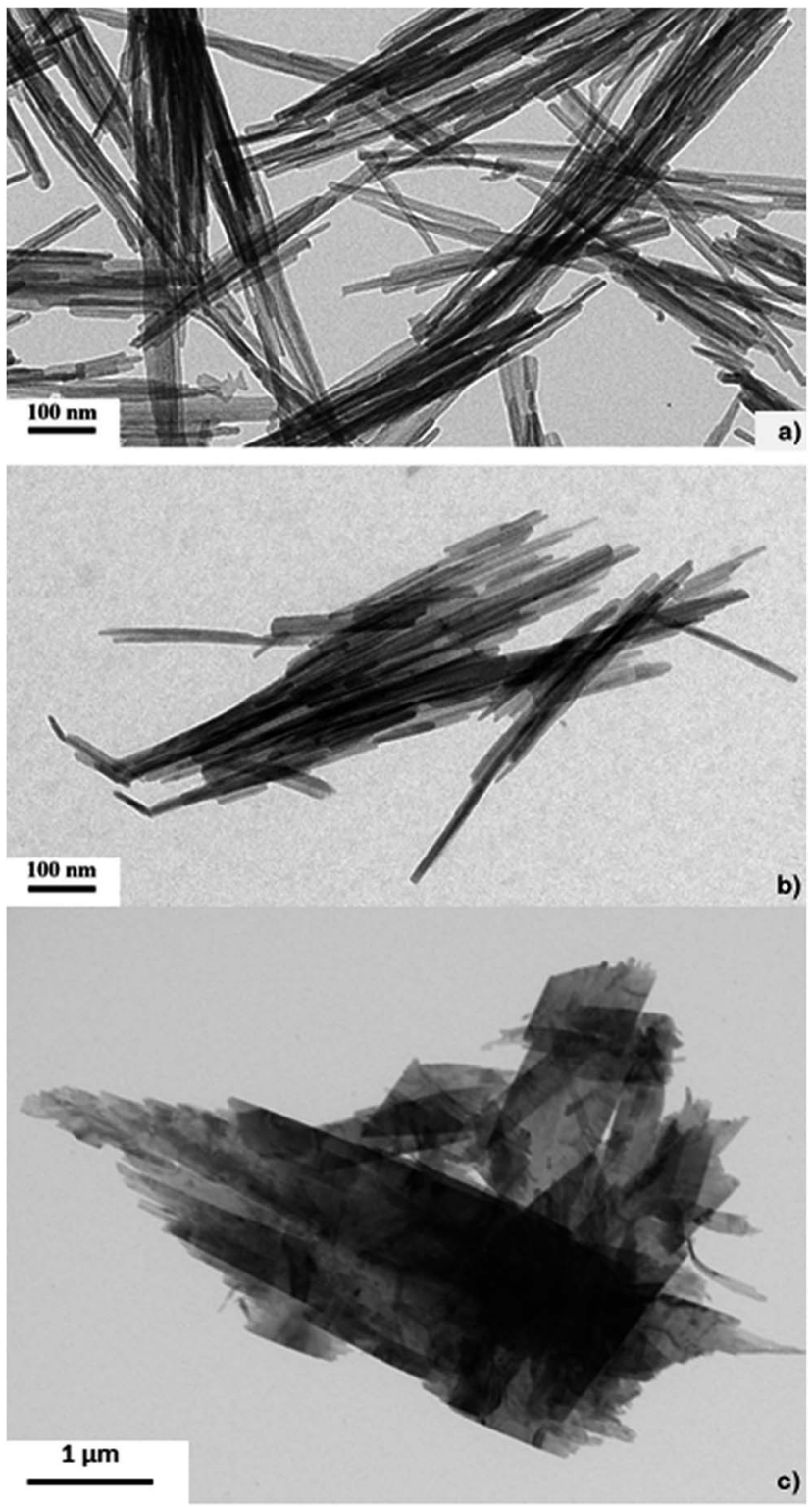

Fig. 2 Bright field TEM image of CUO nanocomposite: (a) with CIL; (b) with $\mathrm{ClL}_{r}$; (c) without ionic liquid.

synthesis (Fig. 2a and b). On the other hand, when $\mathrm{CuO}$ was synthesised without the ionic liquid, the sample has an irregular shape as it can be observed in Fig. 2c. Consequently, we can state that the IL is able to significantly affect the morphology of the nanocomposites also when used as simple additive in water (Fig. 1b). Probably, the strong electrostatic interactions between anions and cations together with the $\pi-\pi$ stacking and van der Waals interactions that involve the imidazolium cations determine the self-assembly of the ionic liquid in the aqueous medium. These organized environments are able to influence the metal oxide nanoparticles growth. ${ }^{30,31}$

STEM images of $\mathrm{ZnO}-\mathrm{CuO}$ nanocomposites show regions of brighter Z-contrast having rounded or acicular forms, inside a uniform matrix (Fig. 3a). EDX analysis performed in those regions (Fig. $3 \mathrm{~b}$ and c) confirms the presence of both $\mathrm{Cu}$ and $\mathrm{Zn}$ 
a)

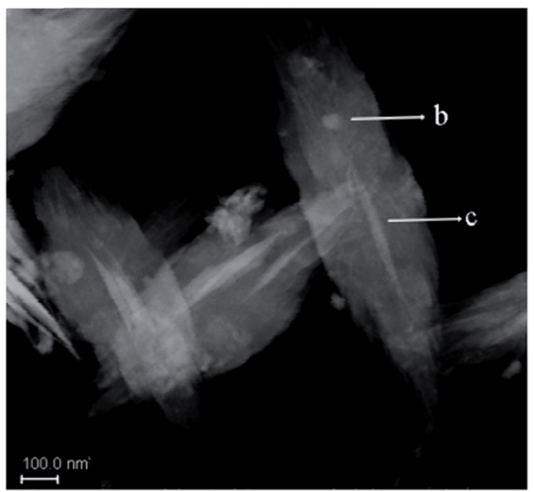

b)

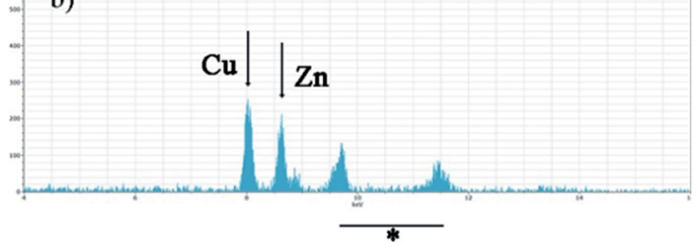

c)

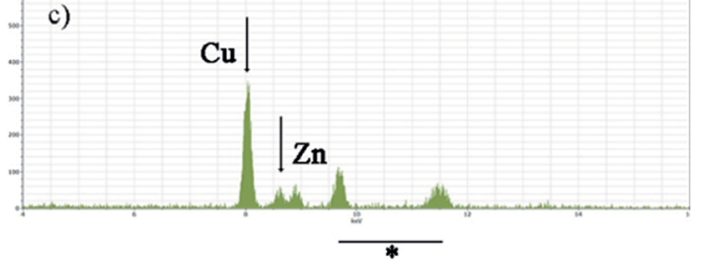

Fig. 3 STEM image and EDX spectra of $\mathrm{ZnO}-\mathrm{CuO}$ nanocomposites. (a) STEM image of three $\mathrm{ZnO}-\mathrm{CuO}$ nanoparticles. Rounded (b arrow) and acicular (c arrow) regions of brighter contrast inside a uniform grey matrix can be easily detected. (b) and (c) EDX spectra collected on the two corresponding regions of (a). Arrows indicate the position of copper and zinc $k \alpha$ respectively, while * indicate the position of $\mathrm{Au}$ peaks due to the gold grid.

in variable concentrations, while in the matrix only copper is detected (data not shown). Therefore, the nanocomposites are formed by a CuO matrix hosting segregation of $\mathrm{ZnO}$.

The phase purity and crystallinity of the metal oxides synthesized was confirmed also by powder X-Ray diffraction (XRD) (see $\mathrm{ESI}^{\dagger}$ ).

In FTIR spectrum (Fig. 4) can be observed a very weak adsorption bands (3100-2900 $\left.\mathrm{cm}^{-1}\right)$ corresponding to the hydrogen bond formed between hydrogen atom at position 2 of the imidazole ring and metal oxide. Strong adsorption bands can be instead observed in the range $700-400 \mathrm{~cm}^{-1}$, which reflect the stretching modes of metal-oxygen bonds. The strong adsorption peak at $544 \mathrm{~cm}^{-1}$ can be assigned to the $\mathrm{Zn}-\mathrm{O}$ stretching bonds.

This peak is slightly shifted to a higher wavelength with respect to the standard absorption spectrum of $\mathrm{ZnO}$ and this feature can be speculatively attributed to the peculiar structure of $\mathrm{ZnO}$ obtained in the presence of the IL. In the case of $\mathrm{CuO}$ nanostructures the strong adsorption bands at 603 and 531 $\mathrm{cm}^{-1}$ are characteristic of the vibration mode of $\mathrm{CuO}$ nanostructures. Indeed, according to Wan et al. an increase of vibration absorption was observed depending on the shape of

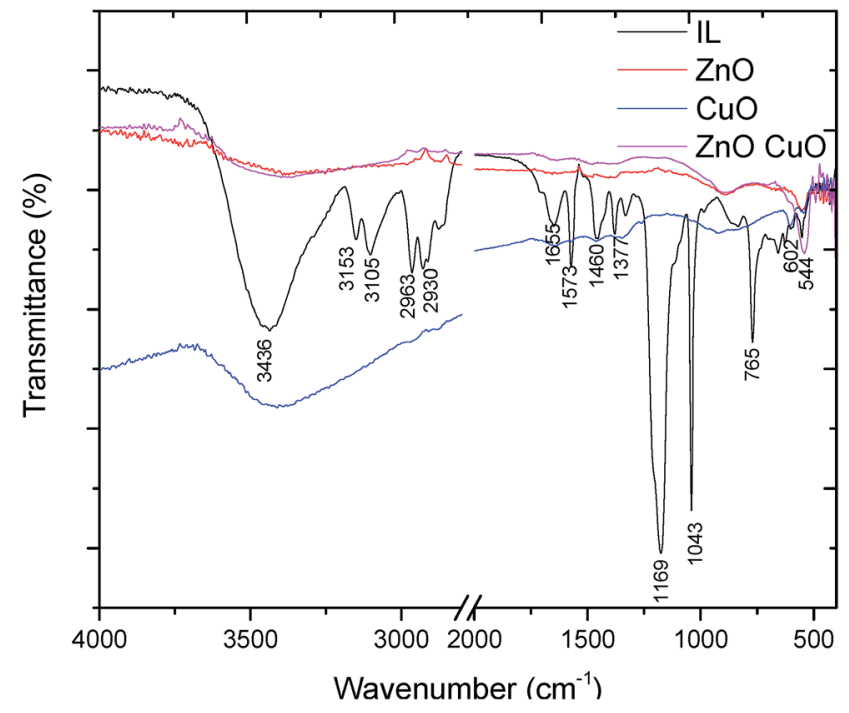

Fig. 4 FT-IR spectrums of the synthesized samples.

the nanostructures (in particular, in the case of tubular sample that had a decreased compactness). ${ }^{32}$ It is known that the particles size depends on the rate of nucleation and growth rate of the product. In this process, IL can exert a double role: (i) it can prevent the agglomeration of the particles; thus, the reaction rate should be slightly slower but sufficient to let the molecules to self-assemble; (ii) the IL might induce a preferential growth of the metal oxide crystal in a particular direction acting like a soft template. Metal oxide (MO) formation is believed to occur through the initial formation of $\mathrm{M}(\mathrm{OH})_{2}$, which in the presence of hydroxide ions gives the corresponding $\mathrm{M}(\mathrm{OH})_{4}{ }^{2-}$ complexes. Dehydration of these latter species under ultrasound or heating gives rise to MO (Scheme 2).

The charged nature of the metal complex involved in $\mathrm{MO}$ formation and the peculiar structure of the IL cation, characterized by a long alkenyl chain, able to give in water micelle-like structures, could tailor the morphology and size of MO structures. The unconventional and very rare properties of ionic liquids that can form extended well-organized hydrogen bonded systems in liquid state, also when mixed with other substances, transform them in supramolecular solvents. A feature this latter, that has been considered the "entropic driver" for spontaneous, well defined and extended ordering of nanoscale structures synthesized in these systems. ${ }^{33}$ On the basis of the obtained results it can be established that the ionic liquid with a natural alkyl chain plays an important role in

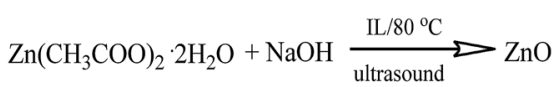

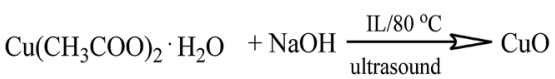

$$
\begin{aligned}
& \mathrm{Zn}\left(\mathrm{CH}_{3} \mathrm{COO}\right)_{2} \cdot 2 \mathrm{H}_{2} \mathrm{O} / \mathrm{Cu}\left(\mathrm{CH}_{3} \mathrm{COO}\right)_{2} \cdot \mathrm{H}_{2} \mathrm{O}+\mathrm{NaOH} \frac{\mathrm{IL} / 80^{\circ} \mathrm{C}}{\text { ultrasound }} \longrightarrow \mathrm{ZnO} / \mathrm{CuO}
\end{aligned}
$$

Scheme 2 Formation mechanism of the metal oxides. 


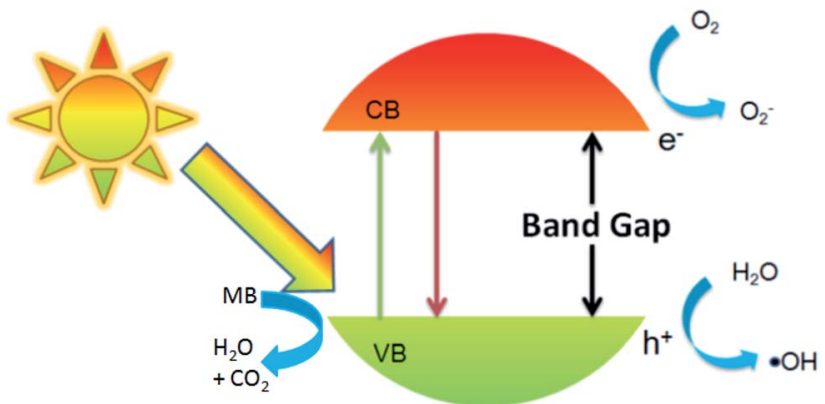

Fig. 5 Schematic representation of the proposed photodegradation mechanism.

directing the shape of the metal oxides. We have observed indeed that in the case of $\mathrm{CuO}$ synthesized without the ionic liquid, but keeping the other conditions unchanged, the morphology was irregular and the structures were also of micrometre order. On the other hand, with the ionic liquid, $\mathrm{CuO}$ has a needle-like shape probably due to the ordering of the ionic liquid structure at the nanoscale level. $\pi-\pi$ stacking and van der Waals interactions, involving respectively the imidazolium cores and the chiral alkyl chains, can determine the self assembly of the ionic liquid in water and affect the selforganization of the metal nanostructures. Related to the particle size, it is well known that this feature depends on the nucleation and growth rate. Although the ionic liquid has polar features it has low surface tension compared with water, thus resulting in a high nucleation rate which is faster than the growth rate. The synthesized $\mathrm{ZnO}, \mathrm{CuO}, \mathrm{ZnO}-\mathrm{CuO}$ nanoparticles were tested in the photodegradation of aqueous solution of MB. The progress of the reaction was measured using an UV-VIS spectrophotometer. A blank experiment in the absence of nanoparticles was also performed. The valence band holes and their electron pair migrate to the surface, where they react with absorbed electrons donors and electron acceptors (water, hydroxide ions) generating surface-bound hydroxyl radicals. The surface $\mathrm{OH}$ radicals can oxidize MB (Fig. 5). On the other hand, the photogenerated electrons from the $\mathrm{CB}$ are scavenged by the molecular oxygen adsorbed on the surface to form superoxide radicals $\mathrm{O}^{2-}$ which can directly react with $\mathrm{MB}$ to be degraded.

The progressive decrease of the absorption band of MB, centred at $\lambda=665 \mathrm{~nm}$, during the photocatalytic degradation under UV irradiation in the presence of $\mathrm{ZnO}, \mathrm{CuO}$, or $\mathrm{ZnO}-\mathrm{CuO}$ is reported in Fig. 6. To evaluate the degradation efficiency, the following equation was applied:

$$
\text { Equation } D \%=\left(A_{0}-A_{t}\right) / A_{0} \times 100
$$

where $A_{0}$ is the absorbance at time zero and $A_{t}$ is the absorbance at time $t$. In Fig. 6, it can be observed the degradation profile of MB without catalyst. The calculated degradation of the sample was approx. $15 \%$ in 60 min. Both $\mathrm{ZnO}$ and $\mathrm{ZnO}-\mathrm{CuO}$ nanoparticles bleach the MB dye. Furthermore, although the mixed oxide nanoparticles have a photocatalytic activity slightly lower than that of the pure $\mathrm{ZnO}$ nanostructures it remains
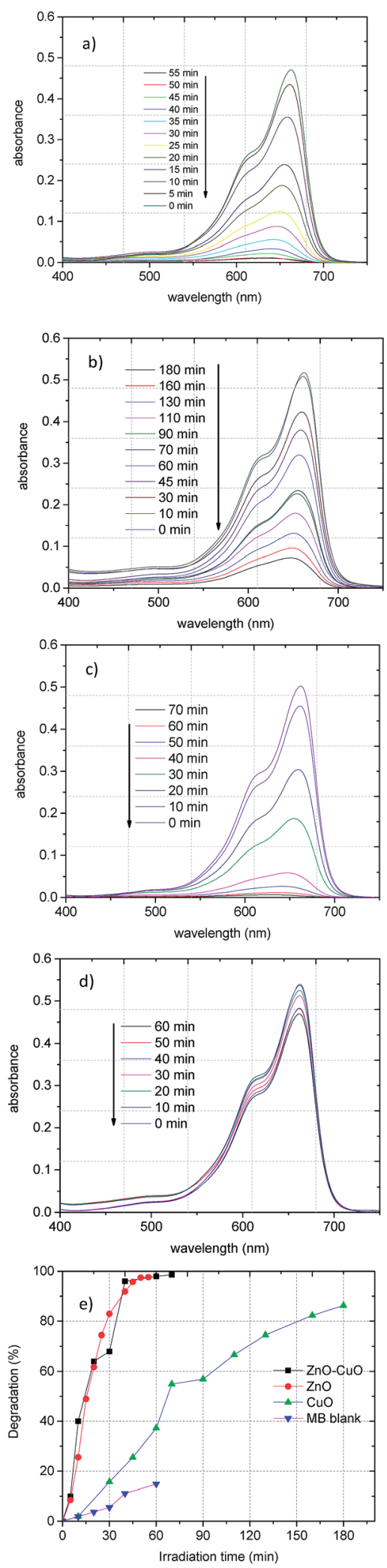

Fig. 6 Adsorption changes in MB photocatalytic degradation for (a) $\mathrm{ZnO}$, (b) $\mathrm{CuO}$, (c) $\mathrm{ZnO}-\mathrm{CuO}$ synthesized with $\mathrm{ClL}$ (d) $\mathrm{MB}$ without $\mathrm{MO}$ and (e) degradation dependence with irradiation time. 


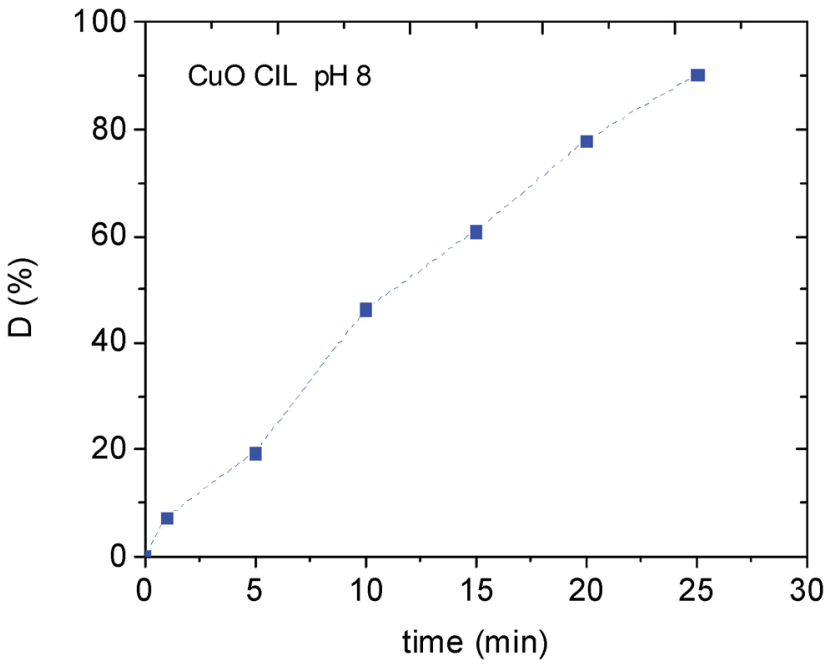

Fig. 7 Photodegradation of $\mathrm{MB}$ with $\mathrm{CuO}$ nanostructure at $\mathrm{pH} 8$.

significantly higher than that of pure CuO. Wan et $a l .^{32}$ observed that an increase in roughness of the employed tubular samples associated to a decrease in crystallinity had a beneficial effect on photocatalytic reaction. Since in the case of needle like $\mathrm{CuO}$ nanostructures the photocatalytic activity was moderate, $80 \%$ in $180 \mathrm{~min}$, we can speculate that this could be not only an effect of the shape of $\mathrm{CuO}$ but also of the smoothness of the needles. The increased compactness of the needle like structure of $\mathrm{CuO}$, decorated with $\mathrm{ZnO}$ nanoparticles, that are acting like catalytic centres could be the reason for which almost $100 \%$ of MB was degraded in $70 \mathrm{~min}$.

Since $\mathrm{CuO}$ had the lowest photodegradation efficiency, we investigated the possible $\mathrm{pH}$ effect using this catalyst (Fig. 7).

Spectroscopic measurements revealed an increased removal of the MB dye by increasing the $\mathrm{pH}$ at 8 (90\% efficiency in only $30 \mathrm{~min}$ ). An analogous behaviour has been recently observed by Seftel et al. investigating the photocatalytic degradation of TiO@ZnAl LDH nanocomposite. This behaviour has been tentatively attributed to an increased electrostatic interaction of the cationic dye with the negatively charged $\mathrm{TiO}_{2}$ nanocomposites. ${ }^{34}$

\section{Experimental}

\section{Ionic liquid synthesis}

(S)-3-(3,7-dimethyloct-6-en-1-yl)-1-methyl-1 $H$-imidazol-3-ium methanesulfonate was prepared by reaction of $N$-methylimidale (50 mmol) with (S)-3,7-dimethyloct-6-en-1-yl methanesulfonate in $\mathrm{CH}_{3} \mathrm{CN}(20 \mathrm{ml})$ at the reflux temperature for $72 \mathrm{~h} .{ }^{1} \mathrm{H}$ NMR $\left(300 \mathrm{MHz}, \mathrm{CDCl}_{3}, \delta\right) 9.31(\mathrm{~s}, 1 \mathrm{H}), 7.52(\mathrm{t}, J=2.4 \mathrm{~Hz}, 1 \mathrm{H}), 7.33(\mathrm{t}, J$ $=2.4 \mathrm{~Hz}, 1 \mathrm{H}), 5.01(\mathrm{t}, J=8.4 \mathrm{~Hz}, 1 \mathrm{H}), 4.23(\mathrm{dt}, J=7.5 \mathrm{~Hz}, J=$ $2.4 \mathrm{~Hz}, 2 \mathrm{H}), 4.01(\mathrm{~s}, 3 \mathrm{H}), 2.72(\mathrm{~s}, 3 \mathrm{H}), 1.93(\mathrm{~m}, 4 \mathrm{H}), 1.63(\mathrm{~s}, 3 \mathrm{H})$, $1.55(\mathrm{~s}, 3 \mathrm{H}), 1.38(\mathrm{~m}, 2 \mathrm{H}), 1.19(\mathrm{~m}, 1 \mathrm{H}), 0.93(\mathrm{~d}, J=7.8 \mathrm{~Hz}, 3 \mathrm{H})$; ${ }^{13} \mathrm{C}$ NMR $\left(75 \mathrm{MHz}, \mathrm{CDCl}_{3}, \delta\right)$ 137.9, 131.7, 124.0, 123.7, 121.7, 48.1, 39.7, 37.3, 36.6, 36.3, 29.8, 25.7, 25.2, 18.9, 17.7. Elemental analysis calcd (\%) $\mathrm{C}_{15} \mathrm{H}_{28} \mathrm{~N}_{2} \mathrm{O}_{3} \mathrm{~S}: \mathrm{C} 56.93, \mathrm{H}$ 8.92, $\mathrm{N}$ 8.85. Found: C 56.87, $\mathrm{H}$ 8.96, $\mathrm{N}$ 8.80. $[\alpha]_{\mathrm{D}}=+11.7\left(\mathrm{CH}_{3} \mathrm{OH}\right)$.
(S)-3,7-dimethyloct-6-en-1-yl methanesulfonate was synthesized as follows: a solution of methanesulfonyl chloride (50 $\mathrm{mmol})$ in $\mathrm{CH}_{2} \mathrm{Cl}_{2}(20 \mathrm{ml})$ was added drop wise at $0{ }^{\circ} \mathrm{C}$ to a solution of alcohol $(S)$-citronellol $(50 \mathrm{mmol})$ and $\mathrm{Et}_{3} \mathrm{~N}(51$ $\mathrm{mmol})$ in $\mathrm{CH}_{2} \mathrm{Cl}_{2}(25 \mathrm{ml})$ during $20 \mathrm{~min}$, then the reaction mixture was stirred at RT for $24 \mathrm{~h}$. The reaction mixture was quenched with an aqueous $\mathrm{NaHCO}_{3}$ solution $(10 \% \mathrm{w} / \mathrm{v})$ and thus extracted with $\mathrm{CH}_{2} \mathrm{Cl}_{2}(3 \times 20 \mathrm{ml})$. The collected organic phases were dried over anhydrous $\mathrm{Na}_{2} \mathrm{SO}_{4}$ and the solvent was evaporated under reduced pressure to give the pure product. ${ }^{1} \mathrm{H}$ NMR $\left(300 \mathrm{MHz}, \mathrm{CDCl}_{3}, \delta\right) 5.06(\mathrm{t}, J=8.3 \mathrm{~Hz}, 1 \mathrm{H}), 4.25(\mathrm{~m}, 2 \mathrm{H})$, $2.98(\mathrm{~s}, 3 \mathrm{H}), 1.97(\mathrm{~m}, 2 \mathrm{H}), 1.67(\mathrm{~s}, 3 \mathrm{H}), 1.68(\mathrm{~m}, 3 \mathrm{H}), 1.59(\mathrm{~s}, 3 \mathrm{H})$. $1.33(\mathrm{~m}, 1 \mathrm{H}), 1.19(\mathrm{~m}, 1 \mathrm{H}), 0.92(\mathrm{~d}, J=7.8 \mathrm{~Hz}, 3 \mathrm{H}) ;{ }^{13} \mathrm{C}$ NMR $(75$ $\left.\mathrm{MHz}, \mathrm{CDCl}_{3}, \delta\right)$ 131.7, 124.3, 68.7, 37.4, 36.9, 34.0, 29.0, 25.8, 25.4, 19.2, 17.7 .

\section{Nanostructures synthesis}

In a typical experiment, to a solution of zinc acetate dihydrate $\left(\mathrm{Zn}\left(\mathrm{CH}_{3} \mathrm{COO}\right)_{2} \times 2 \mathrm{H}_{2} \mathrm{O}, 0.3 \mathrm{~g}\right)$ or/and of copper acetate monohydrate $\left(\mathrm{Cu}\left(\mathrm{CH}_{3} \mathrm{COO}\right)_{2} \times \mathrm{H}_{2} \mathrm{O}, 0.2 \mathrm{~g}\right)$ in $50 \mathrm{ml}$ of deionized water the prefixed amount of the ionic liquid $(0.5 \mathrm{~g})$ was added. Thus, a solution of $\mathrm{NaOH}$ in deionized water $(0.6 \mathrm{~g}$ in $50 \mathrm{ml})$ was added dropwise under continuous stirring. In the case of $\mathrm{ZnO}$ nanoparticles, immediately after the first addition of $\mathrm{NaOH}$ the solution became opalescent and with rising the temperature a white opaque precipitate was formed. In the case of $\mathrm{CuO}$ nanoparticles, the initial transparent blue solution became gradually opaque and finally dark brown, in agreement with the formation of $\mathrm{CuO}$. The obtained solutions were kept at $80^{\circ} \mathrm{C}$ for $1 \mathrm{~h}$ in order to ensure the complete hydrolysis and formation of the desired nanocomposite and then transferred in the ultrasonic apparatus for $2 \mathrm{~h}$. The isolated precipitate was washed with ethanol and deionized water and the product was finally dried in oven at $80^{\circ} \mathrm{C}$. In order to see the influence of the ionic liquid over the morphology of the metal oxides synthesized a control sample was prepared in the absence of the ionic liquid. All isolated samples were characterized by FTIR, UV-VIS and transmission electron microscopy technique (TEM). Moreover, photodegradation tests were performed.

\section{Photodegradation tests}

The photocatalytic response of the prepared nanocomposites was evaluated for the degradation of methylene blue (MB) in aqueous solution. In a photocatalytic trial, $30 \mathrm{mg}$ of metal oxide nanoparticles were suspended in $300 \mathrm{ml}$ of a MB aqueous solution and stirred in dark for 60 minutes to reach the adsorption-desorption equilibrium between the pollutant molecules and the catalyst surface. The concentration of the MB solution was $10^{-5} \mathrm{M}$. Afterwards the suspension was continuously magnetically stirred under UV light irradiation in order to keep the solution homogenous. The samples were irradiated with the light source placed vertically above the sample. At different intervals of time, $5 \mathrm{ml}$ of sample were withdrawn and centrifuged to remove the sediment that might interfere creating light scattering effect. Then absorption spectra of the 
supernatant solution were recorded using a UV-visible spectrophotometer Carry $300 \mathrm{UV}$-VIS with water as reference.

\section{Characterization techniques}

Morphological and chemical composition of the synthesized nanostructures were analysed using a Zeiss Libra 120 transmission electron microscope working at an accelerating voltage of $120 \mathrm{kV}$ and equipped with an in-column omega filter for energy filtered imaging. Energy dispersive X-ray spectroscopy (EDX) analysis were also carried out on the same instrument which is equipped with a Bruker XFlash ${ }^{\circledR}$ 6T | 60 SDD detector. For the TEM analysis the samples were dispersed in ethanol and a drop of the slurry was put on a carbon coated Ni grid for imaging and diffraction and on a carbon coated $\mathrm{Au}$ grid for EDX. Fourier transform infrared (FT-IR) of the samples were recorded in the range of $4000-400 \mathrm{~cm}^{-1}$ at room temperature using a Cary 660 FTIR spectrophotometer. The UV-VIS absorption spectra were recorded with a Cary 50 photospectrometer.

\section{Conclusions}

In summary, we have successfully synthesized $\mathrm{ZnO}, \mathrm{CuO}$ and $\mathrm{ZnO}-\mathrm{CuO}$ nanoarchitectures with special morphology in water by an ultrasound assisted synthesis route at $80{ }^{\circ} \mathrm{C}$ using a hydrophilic ionic liquid. $\mathrm{ZnO}-\mathrm{CuO}$ nanocomposites and $\mathrm{ZnO}$ nanostructures had superior photocatalytic activity towards $\mathrm{MB}$ dye in the presence of UV light irradiation than $\mathrm{CuO}$ nanostructures. This behaviour could be attributed to the different shape compactness and roughness of the obtained nanoarchitectures. This simple approach, requiring only small amounts of IL, will be extended in the future to the production of other mixed metal oxides nanostructures.

\section{Acknowledgements}

The authors would like to acknowledge Sergio Marras for XRD measurements.

\section{Notes and references}

1 R. M. Hewlett and M. A. McLachlan, Adv. Mater., 2016, 28, 3893.

2 O. Bondarenko, K. Juganson, A. Ivask, K. Kasemets, M. Mortimer and A. Kahru, Arch. Toxicol., 2013, 87, 1181.

3 J. Zhou, N. Xu and Z. L. Wang, Adv. Mater., 2006, 18, 2432. 4 R. Marschall, Adv. Funct. Mater., 2014, 24, 2421.

5 P. Pradhan, J. C. Alonso and M. Bizarro, Int. J. Photoenergy, 2012, 780462.

6 X. Zhang, J. Qin, R. Hao, L. Wang, X. Shen, R. Yu, S. Limpanart, M. Ma and R. Liu, J. Phys. Chem. C, 2015, 119, 20544.

7 G. Carja, E. Husanu, C. Gherasim and H. Iovu, Appl. Catal., B, 2011, 107, 253.
8 A. R. Mahjouba, M. Movahedi, E. Kowsari and I. Yavari, Mater. Sci. Semicond. Process., 2014, 22, 1.

9 H. Liu, X. Wu, X. Li, J. Wang and X. Fan, Chin. J. Catal., 2014, 35, 1997.

10 J. Liu, X. Huang, Y. Li, K. M. Sulieman, X. He and F. Sun, Cryst. Growth Des., 2006, 6, 1690.

11 K. Mageshwari, D. Nataraj, T. Pal, R. Sathyamoorthy and J. Park, J. Alloys Compd., 2015, 625, 362.

12 J. Xia, H. Li, Z. Luo, K. Wang, S. Yin and Y. Yan, Appl. Surf. Sci., 2010, 256, 1871.

13 B. Zhang, Z. Xue, Y. Xue, Z. Huang, Z. Li and J. Hao, RSC Adv., 2015, 5, 81108.

14 B. Zhang, X. Zhan, P. Zhao and Z. Li, RSC Adv., 2015, 5, 57640.

15 Y. Qin, Y. Song, N. Sun, N. Zhao, M. Li and L. Qi, Chem. Mater., 2008, 20, 3965.

16 K. L. Luska, P. Migowskia and W. Leitner, Green Chem., 2015, 17, 3195.

17 C. Chiappe and D. Pieraccini, J. Phys. Org. Chem., 2005, 18, 275.

18 P. Wasserscheid and T. Welton, Ionic Liquids in Synthesis, Wiley-VCH, Weinheim, Germany, 2nd edn, 2008.

19 J. P. Hallett and T. Welton, Chem. Rev., 2011, 111, 3508.

$20 \mathrm{H}$. Ohno, Electrochemical Aspects of Ionic Liquids, JohnWiley\&Sons, Hoboken, NJ, 2nd edn, 2011.

21 N. V. Plechkova and K. R. Seddon, Chem. Soc. Rev., 2008, 37, 123.

22 Y. Cui, I. Biondi, M. Chaubey, X. Yang, Z. Fei, R. Scopelliti, C. G. Hartinger, Y. Li, C. Chiappe and P. J. Dyson, Phys. Chem. Chem. Phys., 2010, 12, 1834.

23 C. Chiappe, S. Rajamani and F. D'Andrea, Green Chem., 2013, 15, 137.

24 W. Zheng, X. Liu, Z. Yan and L. Zhu, ACS Nano, 2008, 3, 115. 25 E. K. Goharshadi, Y. Ding, M. N. Jorabchi and P. Nancarrow, Ultrason. Sonochem., 2009, 16, 120.

26 T. Alammar and A.-V. Mudring, ChemSusChem, 2011, 4, 1796-1804.

27 T. Alammar, A. Birkner and A.-V. Mudring, Eur. J. Inorg. Chem., 2009, 19, 2765.

28 A. Jordan and N. Gathergood, Chem. Soc. Rev., 2015, 44, 8200.

29 G. H. Du and G. Van Tendeloo, Chem. Phys. Lett., 2004, 393, 64.

30 R. Rajiv Gandhi, S. Gowri, J. Suresh and M. Sundrarajan, J. Mater. Sci. Technol., 2013, 29, 533.

31 A. H. Jadhav, A. C. Lim, G. M. Thorat, H. S. Jadhav and J. G. Seo, RSC Adv., 2016, 6, 31675.

32 X. Wan, X. Liang, C. Zhang, X. Li, W. Liang, H. Xu, S. Lan and S. Tie, Chem. Eng. J., 2015, 272, 58.

33 M. Antonietti, D. Kuang, B. Smarsly and Y. Zhou, Angew. Chem., Int. Ed., 2004, 43, 4988.

34 E. Seftel, M. Niarchos, C. Mitropoulos, M. Mertens, E. Vansant and P. Cool, Catal. Today, 2015, 252, 120. 